\title{
Prevalence of Bacteria and Intestinal Parasites among Food-handlers in Gondar Town, Northwest Ethiopia
}

\author{
Gashaw Andargie', Afework Kassu², Feleke Moges², \\ Moges Tiruneh ${ }^{2}$, and Kahsay Huruy ${ }^{3}$ \\ 'Department of Health Management and Health Economics, School of Public Health, ${ }^{2}$ Department of Microbiology and \\ Parasitology, and ${ }^{3}$ Department of Medical Laboratory, Gondar College of Medicine and Health Sciences, \\ University of Gondar, PO Box 196, Gondar, Ethiopia
}

\begin{abstract}
Food-handlers with poor personal hygiene working in food-service establishments could be potential sources of infection due to pathogenic organisms. The study was undertaken to determine the prevalence of bacteria and intestinal parasites among 127 food-handlers working in the cafeterias of the University of Gondar and the Gondar Teachers Training College, Gondar, Ethiopia. Fingernail contents of both the hands and stool specimens were collected from all the 127 food-handlers. The samples were examined for bacteria and intestinal parasites following standard procedures. Coagulase-negative staphylococci were the predominant bacteria species $(41.7 \%)$ isolated from fingernail contents, followed by Staphylococcus aureus (16.5\%), Klebsiella species (5.5\%), Escherichia coli (3.1\%), Serratia species (1.58\%), Citrobacter species $(0.8 \%)$, and Enterobacter species $(0.8 \%)$. Shigella species were isolated from stool samples of four foodhandlers (3.1\%). None of the food-handlers was positive for Salmonella species and Shigella species in respect of their fingernail contents. No intestinal parasites were detected from fingernail contents. Intestinal parasites detected in the stools of the food-handlers included Ascaris lumbricoides (18.11\%), Strongyloides stercoralis (5.5\%), Entamoeba histolytica/dispar (1.6\%), Trichuris trichiura (1.6\%), hookworm species (0.8\%), Gardia lamblia (0.8\%), and Schistosoma mansoni (0.8\%); $1.6 \%$ of the study subjects were positive for each of $A$. lumbricoides, T. trichiura, hookworm, and G. lamblia. The findings emphasize the importance of foodhandlers as potential sources of infections and suggest health institutions for appropriate hygienic and sanitary control measures.
\end{abstract}

Key words: Bacteria; Cross-sectional studies; Diarrhoeal diseases: Food-handlers; Hygiene; Intestinal diseases, Parasitic; Parasites; Ethiopia

\section{INTRODUCTION}

Diarrhoeal diseases, mostly caused by foodborne or waterborne microbial pathogens, are leading causes of illness and deaths in developing countries, killing an estimated 1.9 million people annually at the global level. Even in developed countries, an estimated one-third of the population are affected by

Correspondence and reprint requests should be addressed to:

Gashaw Andargie

Department of Health Management and Health

Economics

School of Public Health

Gondar College of Medicine and Health Sciences

University of Gondar

PO Box 196, Gondar

Ethiopia

Email: gashawab@yahoo.com microbiological foodborne diseases each year (1). In contrast, Kaferstein and Abdussalam reported that up to $10 \%$ of the population of industrialized countries might suffer annually from foodborne diseases (2).

However, it can be expected that a large number of illnesses remain under-reported as only the most serious cases are usually investigated. On the other hand, many foodborne illnesses share common symptoms and cannot be distinguished by the symptoms alone. Diagnosis of a foodborne illness can only be made after considering the recent foodconsumption history of a patient and performing proper laboratory tests for disease-producing parasites, bacteria, and bacterial toxins (3). In addition, health departments may not detect food-borne illness for several reasons. Merely, a small propor- 
tion of people infected with enteric pathogens seeks treatment and consequently submits specimens for testing. Even a smaller proportion of people tests positive for a pathogen that healthcare providers and laboratories notify to the health department (4).

Transmission of intestinal parasites and enteropathogenic bacteria is affected directly or indirectly through objects contaminated with faeces. These include food, water, nails, and fingers, indicating the importance of faecal-oral human-to-human transmission (5). Accordingly, food-handlers with poor personal hygiene working in food-serving establishments could be potential sources of infections of many intestinal helminths, protozoa, and enteropathogenic bacteria (6). Food-handlers who harbour and excrete intestinal parasites and enteropathogenic bacteria may contaminate foods from their faeces via their fingers, then to food processing, and finally to healthy individuals (2). Compared to other parts of the hand, the area beneath fingernails harbours the most microorganisms and is most difficult to clean (7). A sudden outbreak of food poisoning due to Salmonella Newport occurred from 31 December 1991 to 4 January 1992 among 344 students, and 23\% of them manifested disease in the study area (University of Gondar), Gondar, Ethiopia (8). Although there was a sudden outbreak long time ago in the University of Gondar, no study was conducted in that area. Therefore, this study was aimed at assessing the prevalence of bacteria and intestinal parasites in food-handlers of Gondar town, Northwest Ethiopia.

\section{MATERIALS AND METHODS}

A cross-sectional study was conducted among 127 food-handlers working in the cafeterias of the University of Gondar and in the Gondar Teachers Training College during 2-27 February 2003. The cafeterias served for 1,553 students, of which $67.6 \%$ were from the University of Gondar, and the remaining students were from the Gondar Teachers Training College. These cafeterias were selected for the study because mass provisions of food service cause a potential source of transmitting infections.

All the food-handlers (47 males and 80 females) working in the cafeterias of the institutes who did not take treatment for any intestinal ailment within the three months prior to the study were included. Seventy-four food-handlers were from the University of Gondar, and the remaining foodhandlers $(n=53)$ were from the Gondar Teachers Training College.
A structured questionnaire was used for collecting information on age, sex, educational level, and hygienic status of each food-handler. Samples of fingernail contents were collected from both the hands of each subject using sterile-moistened cotton-tipped swab and placed into a sterile test tube. Stool sample was collected from each subject in a clean stool cup.

All the samples were cultured into the plates of Salmonella-Shigella agar (Oxoid), MacConkey agar (Difco), and Blood agar (Oxoid). After incubation for 24 hours at $37^{\circ} \mathrm{C}$, the plates were examined, and bacterial species were identified following standard procedures (9). The fingernail contents and stool samples were also examined microscopically for intestinal parasites following direct wet mount preparations in normal saline and iodine solution (10). The formalin ether concentration sedimentation procedure was also followed to check for intestinal parasites in the stool samples (10). Data were entered and analyzed using the Epi Info (version 2000) statistical packages.

\section{Ethical clearance}

Ethical clearance was obtained from the Research and Publication Office of the University of Gondar, and the objective of the study was explained to the study participants to get informed verbal consent.

\section{RESULTS}

The study included all the 127 food-handlers, and the response rate was $100 \%$. The large majority $(72.4 \%)$ of the food-handlers were young adults aged $20-40$ years. Only $58.3 \%$ of the food-handlers had education above elementary school level. Eleven percent of the food-handlers did not practise hand-washing after visiting toilet (Table 1).

Table 2 shows bacterial species isolated from cultures of fingernail contents. Of the 127 samples, cultures of fingernail contents were found to be positive for coagulase-negative staphylococci (41.7\%), S. aureus (16.5\%), Klebsiella species (5.5\%), Escherichia coli (3.1\%), Serratia species (1.6\%), Citrobacter species (0.8\%), and Enterobacter species $(0.8 \%)$. However, no intestinal parasites were detected from the samples of fingernail contents.

Stool cultures revealed the isolation of Shigella species from four (3.1\%) food-handlers. No other enteropathogenic bacteria were isolated from the stools.

Direct microscopic and concentration techniques were used for identifying intestinal parasites from 


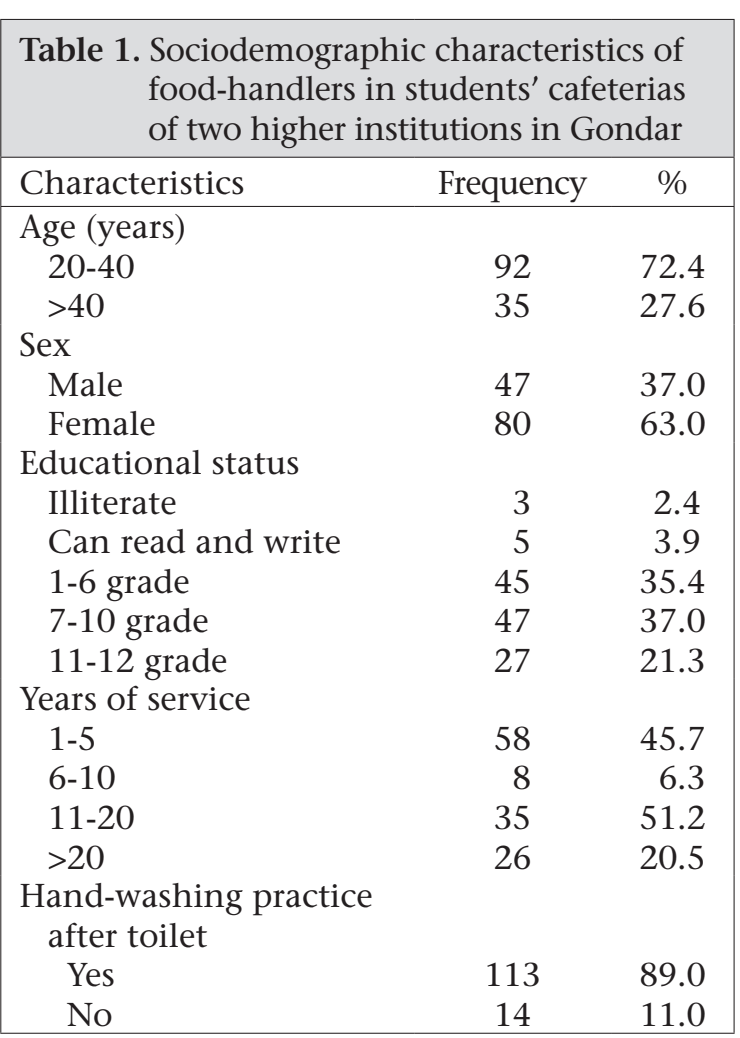

the 127 stool specimens. Thirty-seven (29.1\%) stool specimens were positive for different intestinal parasites. A. lumbricoides was the most prevalent parasite (18.1\%), followed by S. stercoralis (5.5\%) (Table 3); $1.6 \%$ of the study subjects were positive for each of $A$. lumbricoides, T. trichiura, hookworm, and G. lamblia.

\section{DISCUSSION}

In this study, $29.1 \%$ and $3.1 \%$ of the 127 subjects were positive for stool parasites and enteropathogenic bacterial species respectively. In addition, other species of bacteria were also isolated from their fingernail contents. These indicate the health status and very poor hygiene practices of the foodhandlers working in the cafeterias.

Several authors from allover the world have stressed the importance of food-handlers as threats in the transmissions of parasitic and bacterial diseases (1120). In fact, a prerequisite for the control and prevention of intestinal parasitosis and diseases due to enteropathogenic bacteria are a clear understanding of their epidemiology as the information guides in the design of most practical and economic control and prevention measures.

The high (29.1\%) prevalence of intestinal parasites in the stools of the food-handlers in our study was in agreement with the findings of other stud- ies in the region and other parts of the country (21), indicating a high prevalence of soil-transmitted helminths and intestinal protozoans. Such a high prevalence of intestinal parasites is largely due to poor personal hygiene practices and environmental sanitation, lack of supply of safe water, poverty, ignorance of health-promotion practices, and impoverished health services.

Stool cultures of four food-handlers were positive for Shigella species. This may indicate their low educational status and may lead to outbreaks of bacillary dysentery among the student population. Interestingly, Shigella species were isolated from trays which were prepared and ready for use. This may also be a potential source of contamination and outbreaks of disease due to Shigella. The hygiene situation of the food-handlers was further challenged by the isolation of several species of bacteria, including $S$. aureus, and intestinal bacterial species, such as Klebsiella, Enterobacter, and Citrobacter. E. coli and Serratia species were isolated from their fingernail contents, supporting the notion of contamination by faecal bacteria due to inadequate hand-washing of the food-handlers. The poor hygiene practice might have been confounded by the fact that most food-handlers were individuals from the lower socioeconomic class with low level of education. In addition, none of the food-handlers at the facilities had been appropriately trained in safe food-handling practices.

Although stages of intestinal parasites were not detected in the fingernails of food-handlers in the present study, earlier reports showed the presence of ova, larvae, and cysts of intestinal parasites under fingernails of study participants $(12,22-24)$.

One limitation of the study was that, although all the food-handlers were included in the study, the

\begin{tabular}{|c|c|c|}
\hline \multicolumn{3}{|c|}{$\begin{array}{l}\text { Tables 2. Frequency and type of bacteria isolated } \\
\text { from fingernail contents in food-han- } \\
\text { dlers working in students' cafeterias of } \\
\text { two higher institutions in Gondar }\end{array}$} \\
\hline Bacteria isolated & Frequency & $\%$ \\
\hline $\begin{array}{l}\text { Coagulase-negative } \\
\text { staphylococci }\end{array}$ & 53 & 41.7 \\
\hline S. aureus & 21 & 16.5 \\
\hline Klebsiella species & 7 & 5.5 \\
\hline E. coli & 4 & 3.1 \\
\hline Serratia species & 2 & 1.6 \\
\hline Citrobacter species & 1 & 0.8 \\
\hline Enterobacter species & 1 & 0.8 \\
\hline
\end{tabular}




\begin{tabular}{|lcc|}
\hline \multicolumn{3}{|c|}{$\begin{array}{c}\text { Table 3. Type and prevalence of intestinal para- } \\
\text { sites in stool samples of food-handlers } \\
\text { in students' cafeterias of two higher in- } \\
\text { stitutions in Gondar }\end{array}$} \\
\hline Parasite species isolated & Frequency & $\%$ \\
\hline $\begin{array}{l}\text { A. lumbricoides and T. } \\
\text { trichiura* }\end{array}$ & 23 & 18.1 \\
S. stercoralis & 7 & 5.5 \\
E. histolytica/dispar & 2 & 1.6 \\
T. trichiura & 2 & 1.6 \\
G. lamblia & 1 & 0.8 \\
Hookworm and G. lamblia & 1 & 0.8 \\
S. mansoni & 1 & 0.8 \\
Total & 37 & 29.1 \\
\hline *22 study subjects had A. lumbricoides, but only \\
one individual was infected by both A. lumbri- \\
coides and T. trichiura
\end{tabular}

sample size was small, and it was, thus, unable to use advanced analysis to make associations.

The prevalence of enteropathogens from stool specimens, fingernail contents, and intestinal parasites of the food-handlers was high in this study. An effective means of preventing the transmission of pathogens from food-handling personnel via food to consumers is strict adherence to good personal hygiene and to hygienic food-handling practices. It is recommended that education and training in good-hygiene practices should be provided to all food-handling personnel.

\section{ACKNOWLEDGEMENTS}

The authors acknowledge the University of Gondar for financing the study. Their gratitude also goes to the study subjects for their participation in the study.

\section{REFERENCES}

1. Schlundt J, Toyofuku H, Jansen J, Herbst SA. Emerging food-borne zoonoses. Rev Sci Tech 2004:23;513-5.

2. Kaferstein F, Abdussalam M. Food safety in the $21^{\text {st }}$ century. Bull World Health Organ 1999;77:347-51.

3. Plaut AG. Clinical pathology of foodborne diseases: notes on the patient with foodborne gastrointestinal illness. J Food Prot 2000;63:822-6.

4. Kirk M. A manual on food borne illness in Australia. Canberra: Australian Government Department of Health and Ageing, 2005. 47 p.

5. World Health Organization. Prevention and control of intestinal parasitic infections. Geneva: World Health Organization, 1987:7-18. (Technical report series no. 749).
6. World Health Organization. Health surveillace and management procedures of food-handling personnel. Geneva: World Health Organization, 1989: 7-36. (Technnical report series no. 785).

7. Lin CM, Wu FM, Kim HK, Doyle MP, Michael BS, Williams LK. A comparison of hand washing techniques to remove Escherichia coli and caliciviruses under natural or artificial fingernails. J Food Prot 2003;66:2296-301.

8. Asefa A, Mengistu G, Tiruneh M. Salmonella Newport: outbreak of food poising among college students due to contaminated undercooked eggs. Ethiop Med J 1994:32;1-5.

9. Bailay WR, Scott ES. Diagnostic microbiology. $4^{\text {th }}$ ed. Saint Louis: Mosby, 1994.

10. Beaver PC, Jung RC, Cupp EW. Examination of specimens for parasites. In: Beaver PC, Jung RC, Cupp EW, editors. Clinical parasitology. Philadelphia: Lea and Fabiger, 1984:733-58.

11. Tsega E, Nadew FT. The threat of ameobic cyst carriers among hospital food handlers. Ethio Med J 1972;10:43-53.

12. Okubagzhi G. Ova, larva and cyst in fingernail contents. Ethiop Med J 1988;26:33-6.

13. Al-Lahham AB, Abu-Saud M, Shehabi AA. Prevalence of Salmonella, Shigella and intestinal parasites in food handlers in Irbid, Jordan. J Diarrhoeal Dis Res 1990;8:160-2.17.

14. Jonnalagadda PR, Bhat RV. Parasitic contamination of stored water used for drinking/cooking in Hyderabad. Southeast Asian J Trop Med Public Health 1995;26:789-94.

15. Oteri T, Ekanem EE. Food hygiene behaviour among hospital food handlers. Public Health 1989;103:153-9.

16. de Rezende CH, Costa-Cruz JM, Gennari-Cardoso ML. [Enteroparasitoses in food handlers of the public schools in Uberlandia (Minas Gerais), Brazil]. Rev Panam Salud Publica 1997;2:392-7.

17. Yamada S, Matushita S, Kudoh Y. [Recovery and its evaluation of Shigella bacilli or Salmonella from healthy food handlers in Tokyo (1961-1997)]. Kansenshogaku Zasshi 1999;73:758-65.

18. Wiwanitkit V, Assawawitoontip S. High prevalence of positive culture and parasites in stool samples of food handlers in a Thai hospital setting. Med Gen Med 2002; $4: 8$

19. Hundy RL, Cameron S. An outbreak of infections with a new Salmonella phage type linked to a symptomatic food handler. Commun Dis Intell 2002;26:562-7

20. Feglo PK, Frimpong EH, Essel-Ahun M. Salmonellae carrier status of food vendors in Kumasi, Ghana. East Afr Med J 2004;81:358-61.

21. Kloos H, Tesfayohaness TM. Intestinal parasites in 
Ethiopia. In: Kloos H, Zein AZ, editors. The ecology of health and disease in Ethiopia. Oxford: Westview Press, 1993:223-35.

22. Britz L, Krause W. Studies on the incidence of intestinal parasites in children in collectives of the city of Leipzg. Z Arztl Fortbild (Jena) 1965;59:906-13.

23. Guilherme AL, de Araujo SM, Falavigna DL, Pupulim AR, Dias ML, de Oliveira HS et al. Endoparasite pre- valence in truck farmers and in the vegetables of Feira do Produtor de Maringa, Parana. Rev Soc Bras Med Trop 1999;32:405-11.

24. Sahlemariam Z, Mekete G. Examination of finger nail contents and stool for ova, cyst and larva of intestinal parasites from food handlers working in student cafeterias in three higher institutions in Jimma. Ethiopian J Health Sci 2001;11:131-8. 